\title{
OS RISCOS DA INTERNET PARA CRIANÇAS E JOVENS - UM DIÁLOGO URGENTE E INADIÁVEL NA COMUNIDADE EDUCATIVA
}

\author{
THE RISK S OF THE INTERNETFOR CHILDREN AND YOUTH - \\ ANURGENT ANDUNAVOIDABLE DIALOGUE IN THE EDUCATIONAL \\ COMMUNITY
}

\author{
Stephen Bigler \\ Professor de Matemática, Física e coordenador no Colégio Estadual \\ Jornalista Tim Lopes, no Rio de Janeiro \\ https://orcid.org/0000-0001-6365-320X \\ Nilson Antônio Guzzo Junior \\ Professor da Faculdade Salesiana Maria Auxiliadora, em Macaé \\ https://orcid.org/0000-0003-0881-8248 \\ Danielle de Almeida Moreira Candelária Martins \\ Professora de Ciências e Biologia no CSA Leblon \\ https://orcid.org/0000-0002-1174-0974. \\ Cláudio Joaquim dos Santos Braga \\ Universidade Federal do Rio de Janeiro (UFRJ) \\ ORCID: 0000-0002-4060-7435
}

Data de submissão: 25/02/2019

Data de aprovação: 04/04/2019

\section{RESUMO}

$\mathrm{Na}$ Internet, crianças e jovens são atores importantes, porque estão na idade de viver as experiências que não encontram na família, na escola e na comunidade. É nesse sentido que a Internet, como ferramenta da Pós-Modernidade, busca uma qualidade da vida, intelectualização e a desestruturalização do tempo e do espaço, ou seja, fazer uma mesma coisa em tempos e lugares diferentes (simultaneidade), tornando assim a experiência do ciberespaço convidativo e aventuroso, pleno de diversão, mas cheia de perigos, porque não sabemos quem está por trás dos jogos e aplicativos que nossos alunos, filhos, tanto apreciam. Não há neutralidade na Internet, quando sujeitos ativos estão envolvidos na definição dos acontecimentos da vida e coisas. A Internet tornou-se um signo da cidade para pesquisa, cidadania, educação, mas é cheia de contradições, por isso, trazemos neste artigo dados preliminares de campo, para sustentar o problema quanto aos riscos da Internet para crianças e jovens. É urgente que haja um propósito integral que junte tecnologia e educação para valores humanos, diálogo, debate e reflexão como guias importantes contra a nossa própria debilidade e destrutividade.

Palavras-chaves: Internet. Riscos. Crianças. Jovens. 


\section{ABSTRACT}

On the Internet, children and young people are important actors because they are at the age of living the experiences that they do not find in the family, school and community. It is in this sense that the Internet is a unstructured, inviting and adventurous place, full of fun but full of dangers, because we do not know who is behind the games and applications that our students, children so much appreciate. There is no net neutrality when active subjects are involved in defining the events of life and things. The Internet has become a sign of the city, for research, citizenship, education, but it is full of contradictions, so in this article we bring preliminary field data to support the problem of Internet risks for children and young people. There is an urgent need for a comprehensive purpose that brings together technology and education for human values, dialogue, debate and reflection as important guides against our own weakness and destructiveness.

Keywords: Internet. Risks. Children. Youth.

\section{INTRODUÇÃO}

O problema da pesquisa envolve os riscos da Internet para crianças e jovens. Trazemos neste artigo dados preliminares que embasam a investigação para consolidar o problema, com base na norma 510 do Conselho Nacional de Ética em Pesquisa (CONEP).

A propagação das tecnologias da informação e comunicação colaborou para que os momentos de aprendizagem transcendessem o espaço físico da sala de aula, alcançando o ciberespaço, modificando assim as formas como a aprendizagem ocorre, enaltecendo a individualização e a não coletivização de suas ações. Neste sentido, é urgente que as crianças e os jovens desenvolvam valores coletivos, porque valores individuais a família já os ensina. Campanhas, desafios, seminários, encontros de alunos e mesas redondas conduzidas por eles mesmos. A escola e os professores podem ensinar estes valores de cidadania, gestão e de convivência respeitosa.

Ninguém pode conhecer por mim, assim como não posso conecer pelo aluno. O que posso e o que devo fazer é, na perspectiva progressista em que me acho, ao ensinar-Ihe certo conteúdo, desafiálo a que vá se percbendo, e pela própria prática, sujeito capaz de saber. Meu papel de proefessor progressista não é apenas o de ensinar matemática ou biologia, mas, sim, tratando a temática que é, de um lado objeto de meu ensino e de outro, da aprendizagem do aluno, ajudá-lo a reconhecer-se como arquiteto de sua própria prática cognitiva (FREIRE, 2009, p. 125).

O Fundo das Nações Unidas para a Infância (UNICEF) realizou pesquisa com 14 mil meninas com idade entre 13 e 18 anos no Brasil.

A sexualidade da juventude atual inclui práticas de "sexting". Entre as meninas de 13 a 18 anos que participaram da pesquisa 35\% já mandaram fotos ou vídeos íntimos a alguém; mais de $70 \%$ já receberam "nudes" de alguém sem pedir; $80 \%$ já receberam pedidos de alguém para enviar "nudes"; menos de $20 \%$ disseram já ter solicitado "nudes" a alguém; $55 \%$ disseram que essas práticas costumam ocorrer pelo aplicativo WhatsApp; $25 \%$ afirmaram que o "sexting" ocorre pelo aplicativo Snapchat. Mas o vazamento de imagens íntimas traz desafios. Cerca de 10\% das entrevistadas 
passaram por esse problema, sem uma rede de amparo, o que gerou bastante sofrimento (UNICEF, 2019).

Há uma profusão de jogos, grupos de amizade, redes, que envolvem emocionalmente a criança e o jovem, que enredados, e muitas vezes sem o apoio de pais e professores, tornam-se vulneráveis em suas necessidades de desenvolvimento e afeto.

Entre as entrevistadas, 35\% não contaram a ninguém; 31\% falaram para uma amiga; $16 \%$ compartilharam o problema com alguém da família; $2 \%$ conversaram com docentes na escola.Quando questionadas sobre como se sentiram, $80 \%$ disseram ter se sentido culpadas; $30 \%$ disseram ter se sentido tristes e sozinhas; $26 \%$ cogitaram fazer algum dano ao próprio corpo; $3,8 \%$ mudaram de escola; $1 \%$ disse ter mudado de cidade.

A pesquisa deixa claro que existe uma profunda desconfiança das adolescentes em discutir o problema com a família e a escola. Elas preferem silenciar ou falar apenas com amigas, que também têm pouca informação sobre o tema (UNICEF, 2018).

Santaella (2007, p. 14) destaca que não há separação entre mente e corpo quando navega no ciberespaço. Ao contrário, embora o corpo pareça imóvel, enquanto a mente viaja, os sentidos internos do corpo estão em tal nível de atividade, que dá suporte às inferências mentais de quem navega, é um corpo internamente agitado, interagido.

Há um movimento mundial para uma educação padronizada, mas que se diz individualizada, à sorrelfa de uma educação centrada na humanidade. Nós, professores, estamos atentos, mas somos impotentes sem a sociedade civil. Estamos diante da Deuteroeducação, um novo nascimento da educação - de novo - que traduzimos por aprender a aprender. Mas o que está sendo ensinado?

O hábito de procurar por sequências de um tipo do que de outro, o hábito de pontuar a corrente de eventos para produzir repetições de um certo tipo de sentença significativa... Os estudos da mente que chamamos de livre arbítrio, pensamento instrumental, dominância, passividade, etc., são adquiridos por meio de um processo que podemos equacionar como aprendendo a aprender (BAUMAN, 2013, p.159).

É importante concebermos uma ética da responsabilidade na Internet, quando falamos dos riscos a que as crianças e jovens estão expostos, pois o outro, do outro lado da Rede, é também uma parte fundamental da existência da criança e do jovem no mundo.

\section{REFERENCIAL TEÓRICO}

\subsection{Reflexões acerca da Pós-Modernidade}

Não vivemos virtualmente todo o tempo, e a educação precisa preparar para valores da vida comum, pois, nas comunidades em que vivemos, "não podemos defender efetivamente nossas liberdades em nossa própria terra, colocando cercas entre nós e o resto do mundo e cuidando apenas de nossos interesses" (BAUMAN, 2013, p. 31). É preciso ir além de si mesmo; sem o outro, nossas soluções serão pobres, porque serão vazias de algo que não conhecemos, não ouvimos. A escola tem 
Os riscos da Internet para crianças e jovens - Um diálogo urgente e

inadiável na comunidade educativa

um papel de formadora integral na forma de pensar mais abrangente. Quem sabe não seja papel de professores e da escola fundar a diferença entre condicionamento e a determinação?

O mundo não é, o mundo está sendo, como subjetividade curiosa, inteligente, interferidora na objetividade, com que dialeticamente me relaciono, meu papel no mundo não é só o de quem constata, mas também o de quem intervém como sujeito de ocorrências. [...] No próprio mundo físico, minha constatação não me leva à impotência. [...] Constatando, nos tornamos capazes de intervir na realidade, tarefa incomparavelmente mais complexa e geradora de novos saberes do que simplesmente nos adaptarmos a ela. [...] Há perguntas a serem feitas insistentemente por todos nós, e que nos fazem ver a impossibilidade de estudar por estudar (FREIRE, 2016, p. 90).

Nesse novo tempo, a escola está em tempos de dispersão, que aflige educadores comprometidos com a dignidade do ofício do professor em uma era de crise de legitimação do ensino. Um período em que se vive cada vez mais atrelado a um mundo onde os professores estão virando reféns de um ensino que deveria ser libertador.

A educação voltada para uma comunidade fechada, virtual e/ou homeschooling, visa também se proteger dos temores, mas "trancar-se numa comunidade fechada com o objetivo de afastar os temores é como tirar a água da piscina, para garantir que as crianças aprendam a nadar em total segurança" (BAUMAN, 2013, p. 90).

Conforme apontado por Paula Sibilia, em Redes ou paredes, em decorrência do desabamento das antigas hierarquias no seio familiar e escolar, essa indistinção gradual entre os papéis de pais e filhos ou professores e aluno se torna um aspecto importante na dissolução das etapas da vida organizada pela modernidade. O estudante faz do espaço escolar uma extensão de sua casa, confundindo, assim, esfera pública da privada, e com a ambientação da internet essa extensão relacional se amplia para as redes onde estamos conectados e separados.

2.1.1 A Internet nasce sem uma episteme ou já não tínhamos uma Teoria do Conhecimento na base de nossa vida comum?

Em que episteme a Internet se funda? Num mundo globalizado, falsamente hegemônico, a que poderemos comparar a Educação na Internet, quando crianças e jovens sabem usar os jogos mais avançados, mas não são guiados pela lógica da solidariedade, da compaixão? Há alguma luz, um propósito integral no ato de educar o ser humano para o mundo, em cada escola, em cada oficina, em cada casa? Estamos diante de uma educação mais individualista e precisamos suscitar uma nova concepção de vida comum, em condições de produzir normas e esperanças.

Aorganização ameaçada de cima pelo que chamamos de globalização, não pode mais encontrar nela mesma os meios para reerguer-se. É embaixo, num apelo cada vez mais radical e apaixonado ao indivíduo e não mais à sociedade, que procuramos a força capaz de resistir às violências. É neste universo individualista, muito diversificado, que muitos procuram e encontram um sentido que não encontramos mais nas instituições políticas e sociais - e que é o único em condições de produzir exigências e esperanças capazes de suscitar um outra concepção de vida política (TOURAINE, 2007, p. 25).

É urgente que haja um propósito integral na Internet, uma educação que junte tecnologia e a educação para valores humanos, diálogo, debate e reflexão como guias 
importantes contra a nossa própria debilidade e destrutividade.

\title{
2.1.2 Liberdade e cooperação - o viver junto com autonomia
}

A Internet não é sinônimo de barbárie, mas ela está em construção e é um signo aberto a uma nova Hermenêutica. Crianças e jovens são frágeis e ainda não conseguem lidar com sua própria intimidade, o interior de si, e podem ficar enclausurados em si mesmos. Tribos, games na Internet, podem funcionar com uma intencionalidade desconhecida dos pais e professores e levarem crianças e jovens para dentro de si mesmos, num movimento inverso da educação que é estimular o florescimento, a abertura para a vida.

Dentro de tudo o que se falou, é preciso ressaltar que pais e professores precisam conduzir a educação da criança e do jovem fundada em valores humanos, uma matriz, gênese de novas individualidades, menos intimistas, porque oferece a oportunidade de rever a forma e pensar, ser, fazer e conviver, pois sem atenção a estes aspectos pode estar em curso a formação de um ser humano mais intimista, que não enxerga os demais.

\begin{abstract}
Cada pessoa, mergulhada em si mesma, comporta-se como se fora estranha ao destino de todas as demais. Seus filhos e seus amigos constituem para ela a totalidade da espécie humana. Em suas transações com seus concidadãos, pode-se misturar a eles sem, no entanto, vê-los; toca-os, mas não os sente; existe apenas em si mesma e para si mesma. E se, nestas condições, um certo sentido de família ainda permanecer em sua mente, já não Ihe resta sentido de sociedade. (TOCQUEVILLE apud SENNETT, 2001).
\end{abstract}

Todos precisamos aprender uma nova forma de educar com compaixão, compreensão, bem comum - para viver o sentido de uma vida plena, de um aprendizado repleto de significado. A tecnologia é meio e este é o seu lugar.

\section{METODOLOGIA}

A Metodologia que se usou tem uma abordagem qualitativa, teórica, trazendo dados preliminares do campo. A partir de conversas sem registro formal com pais de crianças e jovens, analisamos de forma preliminar os riscos da Internet para este público.

\subsection{Dados Preliminares}

A Resolução $n^{\circ}$ 510, de 7 de abril de 2016, do Conselho Nacional de Ética em Pesquisa, aponta no seu inciso XII para a importância da coleta e análise dos dados preliminares do campo para embasar o problema identificado. Sendo assim, conversamos com seis pessoas com filhos, para identificar a sua percepção dos riscos da Internet para crianças e jovens.

Coletivamente, os estudos mostram que, ao sistematizar os estudos sobre a vida dos adolescentes no contexto do tema de pesquisa, podemos identificar as seguintes tendências que podem ser potencialmente arriscadas: a formação de uma nova cultura de interação, incluindo seus conceitos, valores, pensamentos e meios de expressão. 
Um dos meios de comunicação interculturais novos e insuficientemente
explorados torna-se emoticons (emoticons), novas unidades lexicais
são formadas, ou as antigas são substituídas por novos significados;
as tecnologias de rede ativam principalmente relações interpessoais
superficiais. A participação anônima na comunicação on-line muitas
vezes forma a idéia dos usuários de permissividade e impunidade de
quaisquer manifestações no ambiente de rede, e a estrutura legal
está apenas se adaptando à intensa dinâmica da Internet. Outro
ponto é que os instrumentos de moldar a opinião pública e as
percepções sociais em geral estão mudando da mídia para a Internet
e estão mostrando sinais de desenvolvimento multi-vetorial. Em
outras palavras, sobre a mesma questão é possível obter a informação
mais contraditória, muitas vezes é quase impossível distinguir a
informação "falsa" da real; No contexto da crescente disponibilidade
de informações, os critérios de sua objetividade e confiabilidade são
confusos (PATRAKOV, 2018).

As crianças e os jovens são vulneráveis a este quadro confuso, aparentemente estável. Dentro deste contexto, passaremos a analisar as respostas dadas. Os dados comtemplam um universo de seis pessoas, cujas identidades serão mantidas em sigilo, por força da Norma ANS/CONEP 510.

Consideramos fundamental que estes dados preliminares de campo sejam apresentados e analisados neste artigo, pois estamos entrando a passos largos em uma dobra do tempo que exigirá que saibamos viver com liberdade, autonomia, cooperação e respeito mútuos, porque não importa a ideologia, o nosso destino é comum, e nossas crianças e jovens merecem que saibamos conviver com as novas tecnologias de informação e comunicação.

\section{ANÁLISE E DISCUSSÃO DOS RESULTADOS}

\section{Pergunta 1 - Idade do filho ou filha?}

As idades variaram de 8 a 13 anos. A gradiente de idades é bem interessante, porque nos oferece a oportunidade de ouvir relatos referentes a crianças e jovens que estão se iniciando no mundo das ideias, onde poderão escolher as suas verdades, a moda, os seus interesses.

Um dado interessante é que o Instituto Brasileiro de Geografia e Estatística (IBGE) divulgou, em 2018, os dados da Pesquisa Nacional de Amostra por Domicílio (PNAD) de 2014, e se percebeu que da população de 10 anos ou mais, 77,1\% tinham celular para uso pessoal. O percentual dos usuários de celular para uso pessoal foi mais baixo no grupo etário de 10 a 13 anos (39,8\%), subiu no de 14 a17 anos $(70,0 \%)$. Nota-se que a pesquisa foi feita a partir de uma grade a partir de 10 anos. Porém, basta uma observação em restaurantes da Zona Sul do Rio de Janeiro, Brasil, que há crianças a partir de 4 ou 5 anos usando maciçamente o celular para jogos infantis. A alegação é que assim ficam quietos e deixam os adultos conversarem. Meus filhos, minhas regras! Mas este comportamento está se tornando coletivo e entranhado na cultura, o que merece a atenção de professores e pesquisadores atentos.

Saramago tem razão, não há um resultado final e o destino não está esperando desde o princípio, sem se mover, para referendar a perda da nossa humanidade conjunta. Ora, pelo contrário, o destino hesita muitíssimo, tem dúvidas, leva tempo a decidir-se (SARAMAGO, 1994). Como pais, mães e professores temos tempo. 
Estamos diante da esfinge da Pós-Modernidade, que seduz para ensinar o individualismo, que quer ensinar autonomia como ferramenta isolada do conjunto social. Ela apregoa pelas estradas que cada um siga o seu caminho de forma independente, que cada um cuide de si. Mas Bauman (2008) alerta que 'a dependência e a ética nascem juntas e juntas caem'. Tese e antítese se confrontam na Internet e nas escolas, nas universidades, e as sínteses estão sendo construídas. A contingência, não o determinismo, é a base do nosso complexo presente' (BAUMAN, 2013, p. 64).

Pergunta 2 - Usa a Internet para jogos, participação em grupos como por exemplo usuários de jogos?

A observação e respostas do grupo entrevistado nesta fase preliminar de campo mostrou que tanto crianças como os jovens participam de algum tipo de grupo e são incentivados aos games, principalmente quando os pais querem conversar com os amigos, seja no restaurante ou em casa. Todos estão matriculados em escolas privadas classificadas como " $A$ ", ou seja, têm o inglês como segunda língua nativa e costumam viajar para o exterior nas férias. Perguntei, de forma casual, se essas crianças e jovens demonstravam algum sentimento de compaixão pela dor do outro em algum momento de suas vidas. Não souberam responder e até estranharam a pergunta. Alguns usam a plataforma de jogos online Roblox e Steam.

Professores e pais somos os responsáveis pelo ensinamento de valores, os transmitidos no silêncio, no olhar, no comportamento, na fala, nas regras; sendo assim, temos responsabilidade com nossa forma de agir: incentivar crianças e jovens a serem individualizados, ricos em valores individuais e estimulá-los para que atuem em conjunto com o grupo, para que desenvolvam cooperação e aprendam progressivamente as bases do viver junto de Sennett (2012). A educação integral precisa ser construída tendo como axioma a heterogênese progressiva de si mesma, guiando crianças e jovens para se forjarem livres e cooperativos na incubadora da liberdade individual.

O que virá primeiro: a liberdade ou o viver junto? Bakhtin (2008) diz que a intersubjetividade é anterior à subjetividade. No contexto das teses e antíteses de liberdade e cidadania, cabe ao professor e aos pais - enquanto aprendem - criarem os métodos e diretrizes capazes de integrar liberdade e individualismo à habilidade de cooperar e viver junto!

Pergunta 3 - Você controla os acessos? Você sabe os sites que ele (ou ela) visita, jogos que joga?

Todos disseram que controlam, mas uma pessoa relatou um fato sobre esta complexidade dos riscos da Internet para crianças e jovens. A narrativa foi em torno de fazer parte de um grupo de patins e responder aos desafios e metas para tornar-se líder de grupo. Este foi um dos relatos perturbadores sobre os riscos da internet para crianças e jovens. Para responder aos desafios e metas e tornar-se líder, " $X$ " teve que perder horas de sono; deixar de lado os estudos e, ao final, como não conseguiu manter a pontuação exigida, entrou em depressão. A família começou a estranhar o quadro todo e assumiu a sua responsabilidade, participando de forma efetiva na recuperação de "X". A maioria dos pais respondeu que faz a configuração inicial das contas com controle das senhas de acesso. No todo, acessam a internet através dos dispositivos utilizados (celular do pai ou da mãe, tablet da criança ou jovem, console de videogame PS4, computador da casa). Principais usos: celular (Braw Stars), Youtube (Felipe Neto, Casal Nerd, Autentique Games), PS4 (Fortnite), computador (plataforma Roblox, Steam, Undertale).

É a era da informação na Internet. Essas crianças e jovens são muito conectadas e quando enfrentam problemas não procuram os pais, nem os professores, muito menos a escola. Confiam nos amigos. O problema reside no fato de que há ausência 
de uma orientação geral sobre Internet, plataformas digitais e mídias sociais, o que não favorece o acolhimento do jovem e da criança diante de um problema que esteja enfrentando, e aí ele busca, muitas vezes, o amigo na Rede social.

Pergunta 4 - Ele (ou ela) faz aula de computação?

Os pais também relataram que as crianças e jovens estão fazendo curso de computação, aprendendo a se relacionar na Internet e a fazer "games". Explicaram que é uma exigência da criança ou do jovem, para competir com os coleguinhas da escola .

Na verdade, vivemos imersos em uma cultura de competição, em sala de aula, no dia a dia, e isto já faz parte do nossos ser e ensinamos isto aos alunos e aos filhos, de forma tácita, sem palavras. A cooperação, não a competição deveria ser ensinada, e cooperação exige solidariedade, compaixão, respeito ao outro, empatia.

Pergunta 5 - Na casa dos amigos do seu filho ou filha, as regras de acesso e controle são iguais às suas?

Minha casa minhas regras", mas na casa dos outros, as regras às vezes são diferentes. Em geral, as crianças e jovens usam a Internet em games, quando estão juntos, e os pais consideram que faz parte da vida deles. Normalmente, nestes fins de semana os pais ficam na sala conversando e, às vezes, um deles vai olhar as crianças ou jovens, afirmam que perguntam sobre o que estão fazendo, qual é o jogo, afirmam que acompanham, e, como não veem nada de estranho, voltam para a sala.

Houve uma mudança no mundo, e está em curso uma Pós-Modernidade que estimula a levar uma vida individualizada, e neste contexto houve uma transformação dos vínculos entre a escola e alunos, e há uma énfase na formação tecnica. É preciso que a escola exerça o papel de uma ouvidora atenta.

O conceito e pesquisas sobre Risco da Internet para crianças e jovens pode nos ajudar a entender a medida da experiência atual com a Rede. E é bom lembrar que, sem que se faça um amplo debate sobre o tema, os pais e professores não serão capazes de responder aos riscos e à incerteza deste tipo de acesso.

Pergunta 6 - Você percebe mudança de comportamento durante ou depois do uso dos jogos que ele (ou ela) usa?

Todos foram unânimes em responder que, às vezes, a criança ou o jovem fica irritado após o uso do game. Ficam mais agitados durante o uso de alguns dos seus jogos (Fortnite e Undertale). Nestes jogos, ao ser demandado de desligar, em função do término do horário de jogar ou da necessidade de iniciar outra atividade, ele fica bastante frustrado, pede mais tempo ou expressa ter ficado chateado.

A profissão do professor é complexa, os pais querem ajudar os filhos a se modernizarem tecnologicamente, mas, na natureza do trabalho da educação, há conflitos de valores entre escola, família, a própria mídia, e os valores podem ser contraditórios. Por este motivo, precisamos de laços entre a escola e os pais para que a educação de jovens e crianças se desenvolva de forma integral.

Pergunta 7 - Seu filho (ou filha) Ihe contaria se estivesse sofrendo algum tipo de bullying, abuso ou ameaça na Internet?

Todos afirmaram que sim; no entanto, o familiar que falou sobre o grupo de patins reiterou que não percebeu de início o problema que " $X$ " estava enfrentando, pois era tímido e, com a participação neste grupo, tornou-se mais exuberante e com hábitos de liderança, como dirigir a sua própria vida em casa, cooperando com as tarefas de casa. Afirmou que a família sempre acompanhou o uso da Internet em grupos ou games. Só bem depois, perceberam e estranharam o comportamento arredio de "X", 
com olhos cansados e baixo rendimento na escola. Esta narração foi feita com muita emoção.

Cada família possui o seu ambiente, a sua cultura, as suas questões e nenhuma escola ou professor se propõe a definir um padrão em Educação, mas é preciso um amplo debate nas escolas com as famílias, crianças e jovens, para que se percebam os desafios que nos traz este novo momento de imersão no mundo virtual.

Os desafios à educação [...] terão que surgir do interior das culturas
de cada região. A educação deve refletir o melhor e mais autêntico de
nós próprios e de nossas sociedades. Só assim pode tender a unir
todos os seres humanos em torno de valores universalmente
compartilhados em defesa de seus interesses comuns. Em todas as
partes e, sob qualquer ponto de vista, a educação é essencial para a
paz. A paz que, como sabemos, é mais que a mera ausência de
conflito. É uma cultura baseada na tolerância e no respeito aos
demais: é um espírito de solidariedade ativa entre os indivíduos, que
se fundamenta em uma esperança comum de justiça e de paz.

Pergunta 8 - Você notou alguma baixa de rendimento na escola associado ao uso de games de Internet?

Os pais do jovem do grupo de patins afirmaram que durante o tempo em que fez parte do grupo, ele oscilava entre euforia, por estar liderando uma equipe, e depressão, quando não conseguia alcançar os pontos e perdia a meta. O jovem baixou o rendimento escolar, passou a dormir pouco, os olhos estavam sempre cansados e a família começou a perguntar e, diante das negativas, uma tia ficou mais próxima para acompanhar e ver o que estava acontecendo. A confiança nesta tia fez com que o jovem relatasse o que estava ocorrendo e aceitasse a ajuda que ela ofereceu. Ela o acolheu, e isto foi fundamental.

As novas plataformas digitais e as mídias sociais estão engendrando mudanças que colocarão as famílias e as escolas frente a novas fronteiras de conhecimento. Qual o papel desta geração para que o conhecimento possa ser usado a favor da humanidade? Escolheremos uma educação para a técnica? Para a transformação social? Optaremos por uma educação que desloque da tecnologia para as crianças e jovens o centro das necessidades do desenvolvimento da sociedade?

Piaget (1970, p. 311) afirma que "A inteligência (...) organiza o mundo organizando a si mesma...". Professores e pais temos que abraçar esta responsabilidade de formar nossos alunos e filhos para que eles, com autonomia e de forma colaborativa, se formem para o mundo.

\section{CONSIDERAÇÕES FINAIS}

É preciso interpretar as lacunas, os silêncios, é preciso se incomodar com o outro, é preciso se inquietar com o próximo, porque "ele está perto de nós, não importa o lugar onde esteja, ele esta perto de mim, como o primeiro a chegar. É como se fosse o único" (POIRÉ apud BAUMAN, 2008).

É preciso uma nova mentalidade para compreender o poder das vizinhanças, o poder do networking, o poder dos grupos de relacionamento e suas implicações no comportamento individual da criança e do jovem.

Um novo ser está sendo gestado, e novas relações surgem na mente humana, mas professores e pais não temos respostas, só indagações e precisamos, enquanto 
sociedade, definir a educação que queremos para nossas crianças e jovens. Por isso, a Educação depende da harmonia e cooperação entre famílias, escolas, crianças e jovens. É nesta medida que temos de criar as condições especiais desta temporalidade e desta situacionalidade, para responder à complexidade de uma nova visão em Educação, que não esqueça a humanização e que não descura da necessidade de preparação técnica do indivíduo.

A dimensão de Educação a que nos referimos destaca crianças e jovens empreendendo um novo processo de aprendizado, com cidadania, que considera a história de cada família e sua cultura, e os insere no campo da linguagem, uma nova linguagem, que junta técnica, tecnologias, valores culturais. Parafraseando Paulo Freire (2009), é preciso que cada jovem, cada criança assuma o papel de sujeito de sua inteligência do mundo e não apenas de recebedor do que the foi ensinado ou transferido".

Notem vocês que se eu tivesse dito: a linguagem é nosso instrumento de comunicação, teria colocado a linguagem no corpo, como instrumento através do qual manejamos símbolos na comunicação. Reconheço também que a linguagem não se dá no corpo, mas sim no fluir em coordenações consensuais de conduta.

Estamos compartilhando na Internet uma nova forma de exercício da cidadania ou sua ausência, e é bom lembrar que nosso destino é compartilhado.

\section{REFERÊNCIAS}

BAKHTIN, Mikhail. Dialogismo e construção do sentido. Organização: Beth Brait. São Paulo: Editora Unicamp, 2008.

BAUMAN, Zigmunt. Sociedade individualizada: vidas contadas e histórias vividas. Rio de Janeiro: Zahar, 2008.

BAUMAN, Zigmunt. Cultura no mundo líquido moderno. Rio de Janeiro: Zahar, 2013.

BENDASSOLI, Pedro Fernando. Identidade e trabalho em tempos sombrios. São Pailo: Ideias e Letras, 2007.

BERTALANFFY, Ludwig Von. Teoria Geral dos Sistemas. Petrópolis: Vozes, 2015.

DEBORD, Guy. A Sociedade do espetáculo. Rio de Janeiro: Contraponto, 1997.

FREIRE, Paulo. Pedagogia da autonomia. São Paulo: Paz e Terra, 2009.

FREIRE, Paulo. Pedagogia da indignação. São Paulo: Paz e Terra, 2016.

GÓES, Maria Cecília Rafael. A formação do indivíduo nas relações sociais: contribuições teóricas de Lev Vigotski e Pierre Janet. Educação \& Sociedade, ano XXI, n.71, Jul. 2000. Disponível em: http://www.scielo.br/pdf/es/v21n71/a05v2171.pdf.

LEÃO, Emmanuel Carneiro. Filosofia contemporânea. Petrópolis: Daimon, 2013.

MORETTO, Vasco Pedro. Construtivismo a produção do conhecimento em aula. Rio de Janeiro : DP\&A Editora , 1999.

ORGANIZAÇÕES DAS NAÇÕES UNIDAS. UNICEF: meninas que têm imagens íntimas 
vazadas precisam de redes de apoio. 2019. Disponível em: https://nacoesunidas.org/ unicef-meninas-que-tem-imagens-intimas-vazadas-precisam-de-redes-apoio/.

PAIVA, Raquel. O espírito comum : comunidades, mídia e globalismo. Rio de Janeiro: Mauad, 2003.

PATRAKOV , Eduard, Head of research laboratory of social safety, assistant professor of Department of Innovation Studies and Intellectual Property, Ural Federal University (Russia), e-mail: e.v.patrakov@urfu.ru. Cross-Cultural Study of The Representations of Teachers About Internet Risks for Adolescents. Palestra realizada no Brasil em 26/11/2018 - Anotações do Seminário, Rio de Janeiro: Unicarioca. 2018

SANTAELLA, L. Linguagens líquidas na era da mobilidade. São Paulo: Paulus, 2007

SENNETT, Richard. O Declínio do homem público. Rio de Janeiro: Companhia das Letras, 2001.

SENNETT, Richard. Juntos: os rituais, os prazeres e a política da cooperação. Rio de Janeiro: Record, 2012.

VYGOTSKY, L.S. A formação social da mente. São Paulo: Martins Fontes, 1998.

VYGOTSKY, L.S. Pensamento e linguagem. Trad. M. Resende. Lisboa: Antídoto, 1979.

VYGOTSKY, L.S. A formação social da mente. Trad. José Cipolla Neto et alii. São Paulo, Livraria Martins Fontes, 1984. 